\title{
SEPARATION: CONSEQUENCES FOR WEALTH IN LATER LIFE
}

Caroline Dewilde, Karel Van den Bosch, Aaron Van den Heede 


\title{
9 Separation: Consequences for Wealth in Later Life
}

\author{
Caroline Dewilde, Karel Van den Bosch and Aaron Van den Heede
}

\subsection{Separation as an increasingly important issue}

Over the course of their lives, a substantial minority of elderly European men and women have experienced the dissolution of one or more partner relationships through divorce or the ending of cohabitation. So far, most research into the economic consequences of (marital) separation has been based on panel data and consequently focuses on the short or middle term for the current generations of respondents in their 'adult' years. This chapter makes a start at improving existing knowledge by studying the economic consequences of (marital) separation, looking at this issue 'from the other way around'. Using retrospective SHARELIFEdata, we explore how wealth in later life - measured in terms of home-ownership and the possession of other financial assets - is influenced by the relationship trajectories of European men and women. Given the complexity of the issue at hand, in this chapter we focus on the first marital separation. As for the variation between European countries in terms of the institutional arrangements influencing the short and long-term consequences of (marital) separation, we furthermore sketch the contours of a conceptual framework that can be used for a more indepth study.

Although in recent years the economic consequences of (marital) separation have been the topic of a fair amount of publications, most authors have concentrated on the short or middle-term impact of this life event. The results of these studies for different European countries are fairly consistent: while many divorced women become financially deprived and/or even end up claiming welfare, for men the financial consequences of divorce are usually less negative - controlling for the size and the composition of their new household, some men even experience an improvement of their disposable income. These gender differences can be related to the gender division of labour, the gender differences in labour market participation and male-female wage differentials. From a comparative perspective, Uunk (2004) has shown that in countries providing either high public childcare and/or generous transfers for lone parents, the short-term economic consequences of divorce are less severe. Furthermore, not all women follow the same income trajectory during the years following divorce. According to Andreß et al. (2006), British and German women, although they suffer more initially, recover rather quickly from the negative economic consequences of separation, perhaps because their economic situation forces them to repartner more quickly. In Sweden how- 
ever, where gender equality in terms of a comparatively smaller income loss following separation is most pronounced, both men and women seem to financially suffer for a longer period of time. This might be an indication that in the longer term the incomes of separated women gradually recover, though not always to their previous levels. The mechanisms by which the initial decline in household income following (marital) separation is mainly countered are paid work and/or repartnering. Across Europe, women who repartner experience a 26\%-increase of their post-divorce income, while women who enter the labour market gain 19\% (Dewilde and Uunk 2008).

This focus on (women's) income position has resulted in a somewhat one-sided view of the economic consequences of (marital) separation. In addition to the financial consequences, divorce entails significant additional economic changes. Perhaps the main other economic impact concerns the housing situation of the expartners. By definition, the dissolution of the couple results in two separate households, of which at least one has to find another place to live. Setting up a new household comes at a substantial cost, and in particular for those people at the lower end of the income distribution, finding new housing which is both affordable and meets certain quality standards is a difficult task. Likewise, the partner who remains in the marital home often has to provide for the full mortgage or rent payments, which can cause severe financial strain and/or result in moving away. Many respondents, especially women, have difficulties coping with housing costs and maintenance, or find that they do not manage to raise the capital necessary to buy their ex-partner's interest in the house.

Comparative research on the housing consequences of (marital) separation (Dewilde 2008, 2009) shows that in the short-term, this life event substantially raises housing costs, as well as the risk of leaving owner-occupation for both men and women. This risk seems however smaller for women in those countries where the economic consequences of divorce are more severe, i.e. in the liberal and Southern-European welfare regimes. This finding might be explained by the fact that women in these countries might be compensated for the economic consequences of divorce by more advantageous procedures of property settlement. However, other explanations are possible as well. In the Southern-European countries, outright ownership is more common and part of the 'extended family enterprise', which makes it easier to remain in owner-occupation. Furthermore, alternative forms of housing are limited, so that divorced men and women might be forced to stay in owner-occupation, even if they cannot afford it.

\subsection{In the long term}

Concerning the long-term consequences of (marital) separation, our first hypothesis is that both men and women who ever experienced the dissolution of a marriage or cohabitation are less likely to be a home-owner and have a lower level of 
financial assets in old age, even when they have eventually repartnered. This effect is caused by three underlying mechanisms. The first mechanism relates to the event of (marital) separation itself. As the previous section has shown, across Europe (marital) separation results in a decline of disposable household income (especially when taking housing costs into account) for a usually extended period of time, and in the exit out of owner-occupation. We also expect to find a gender difference in the impact of (marital) separation in old age. The second mechanism is related to the well-known beneficial effect of marriage. Wilmoth and Koso (2002) found that marriage, as the institutionalised way of cohabiting, offers more opportunities for welfare accumulation compared to other living arrangements. Thirdly, especially in so-called home-ownership countries, owner-occupation is heavily subsidised through tax credits, benefiting average- and high-income households. Moreover, during the post-war decades, most European countries have experienced a more or less sustained increase in house prices, making owneroccupation a relatively safe and profitable investment. To the extent that renters do not enjoy the same financial benefits, the event of exiting owner-occupation in itself following (marital) separation simply puts separated men and women in a position where they can accumulate less wealth.

\subsection{The Importance of Institutions}

The impact of divorce obviously depends on the social context. A historical and comparative perspective is therefore important. In this section we single out two dimensions: the welfare state and the legal traditions concerning the division of marital property. Furthermore, as the respondents in the SHARELIFE-module grew up, established their families and bought their homes in different time periods, we have to take into account that processes and mechanisms of wealth accumulation (both housing wealth and other financial wealth), as well as the impact of (marital) separation on these, might be different for different birth cohorts. Therefore, in our analyses we distinguish between respondents born from 1900 to 1934, from 1935 to 1944 and from 1945 onwards.

Concerning the possibly mitigating influence of the welfare state on the impact of (marital) separation on wealth in old age, we expect that female labour market participation can be regarded as a reflection of the opportunity structure for women. This is influenced by welfare state interventions in matters like public child care and maternity benefits, but also by education and legislation towards non-discrimination at the work place. Of course, cultural and economic factors are also important. In our empirical analysis, we use the female labour market participation rate in 1980 as a kind of 'catch-all' contextual variable for this opportunity structure. This choice is mainly motivated by the lack of data on specific welfare state interventions in the earlier decades for all countries. In any case, we expect that women in countries with high female labour market participation are more 
likely to be economically independent, and therefore suffer less from negative consequences on their wealth after separation.

A second institutional domain we at least want to draw attention to concerns the legal customs related to the division of marital property. So far, this domain has remained a black box, and is not often addressed by sociologists. From a comparative perspective however, laws and legal customs potentially have a large impact on the effect of marital separation on wealth in old age. Issues such as compensation for the 'wronged' spouse in terms of facilitating ownership of the family home or the sharing of pension rights have a large impact on economic well-being and the possibilities for wealth accumulation for both separated men and women. Furthermore, the change from bilateral to unilateral divorce laws might have an impact on the economic outcomes in later life remains. These questions however remain unanswered up to today as research is still scant on these issues.

\subsection{Data and Variables}

The data used in this chapter are based on the marital histories collected in SHARELIFE. These retrospective data are then combined with the prospective data collected during the second wave of SHARE. The main reason for combining the SHARELIFE data with the second wave of SHARE is that the dependent variables we use as indicators for economic well-being were not collected in SHARELIFE. The data refer to the life histories of 28,573 respondents in 13 countries (Austria, Germany, Sweden, The Netherlands, Spain, Italy, France, Denmark, Greece, Switzerland, Belgium, Poland and the Czech Republic). Using listwise deletion, cases with missing information on the variables of interest were removed from the sample, producing an analytical sample that contained a total of 20,711 respondents, including 4,552 currently singles and 16,159 currently married or cohabiting individuals. In the following paragraphs we discuss our main variables and our analysis strategy.

\section{Dependent Variables}

Our analyses focus on home-ownership and the total net worth (i.e. wealth) of SHARELIFE-respondents. Home-ownership as recorded in the second wave of SHARE is measured as a dichotomous variable, coded 0 if a respondent does not own the house he or she occupies at the time of interview and coded 1 if he or she does. The total net worth is the sum of the net values of: (a) the primary residence net of the mortgage, (b) other real estate, (c) business, (d) cars, (e) savings, stocks and bonds, mutual funds, IRA's and life insurances. Imputations on net worth are provided in the SHARE-data to correct for missing values. This net worth is expressed in PPP-adjusted Euros. It is important to note that in SHARE net worth is measured at the household level. This is problematic for our analysis since it im- 
plies that net worth is confounded with current marital status. For couples, the total net worth represents the wealth of two adults, whereas for singles it reflects the wealth of one adult. Given our goal of estimating the effect of individuals' marital histories on their economic well-being in later life, we need to adjust for this by creating a per capita measure of total net worth as dependent variable. To do so we assign half of the total household net worth to each partner by dividing the household level wealth by the number of people living in the household. After inspection of the data we applied a logarithmic transformation of our dependent variable, net worth, to correct for the non-normal distribution. To avoid the loss of respondents with negative or zero net worth values, we added a constant to the total wealth distribution to anchor the minimum value at 1 before applying the $\log$ transformation. Using the logged net worth changes the interpretation of the continuous coefficients, which can now be interpreted as percentage changes. Dummy variables, however, cannot easily be interpreted as percentage changes. Following Halvorsen and Palmquist (1980), the coefficients for the dummy variables are transformed by taking the antilog of the coefficient, subtracting 1 from this antilog and multiplying the result by 100 to obtain percentage changes.

\section{Independent Variables}

Since the main goal of this study is to examine the long-term effect of different marital trajectories on economic well-being, we created marital status categories based on the current marital status and the previous marriage dissolutions and remarriages. The two possible current marital statuses are married/cohabiting or single. Non-cohabiting couples were grouped in with singles (236 respondents). We grouped respondents that are married, but living separated from their spouses, in with married respondents (22 respondents). Grouping the currently married or cohabiting individuals according to their marital history results in four categories: (1) the continuously married/cohabiting (reference), (2) individuals who never married, (3) remarried after experiencing at least one divorce, and (4) cohabiting after experiencing at least one divorce. We distinguish between three categories of singles: (5) never married, (6) single after experiencing at least one divorce and (7) single following widowhood. We excluded individuals who experienced a combination of widowhood and divorces (329 respondents) and individuals who remarried or cohabited after the death of a partner because of the small sample numbers (350 respondents). We also excluded the individuals for whom we could not identify marital history (751 respondents) and those who cohabited but never married (181 respondents). Note that this reconstruction of marital history does take into account neither the sequence nor the number of dissolutions. Another important note is that the results for the groups of cohabiting divorcees and widows and widowers should be interpreted with caution because of the small numbers. 
The institutional effects of the different welfare states are estimated using the percentage of female labour-force participation in all countries in 1980, the earliest year for which we have data for all countries (ILO, 2010).

\section{Control Variables}

In all models we control for age, age squared, birth cohort (1900-1934, 19351944, 1945-...), education (Low, Medium, High), subjective health (Very Good to Excellent, Less than Very Good), number of chronic diseases, number of living children, number of siblings, the degree of urbanisation, and the European region one is living in: (1) North (Sweden, Denmark, The Netherlands); (2) West (Austria, Germany, Belgium, France, Switzerland); (3) South (Spain, Italy, Greece); and (4) East (Poland, Czech Republic) as dummy variables.

\subsection{Results}

Let us first look at the distribution of the sample across marital history categories. Figure 1 shows that a large proportion of our sample is still in their first marriage (66 percent overall). 30 percent experienced a marital dissolution, while 4 percent never married or cohabited. The dominant reason for marital dissolution for women born before 1945 and men born before 1935 is widowhood; for later cohorts divorce becomes more important, which reflects the increasing divorce rates since the 1960s. Among men, about half of the divorcees are currently remarried (53 percent), while 33 percent is currently single and 13 percent found a new partner, but did not remarry. Among female divorcees, the proportion that is still single is much larger. About 55 percent is still single after experiencing a divorce. While the number of women who cohabits after divorce is quite comparable to that of men (10 percent), the number of remarried women is relatively small (34 percent).

Figure 9.1: Distribution of marital history by birth cohort and gender 

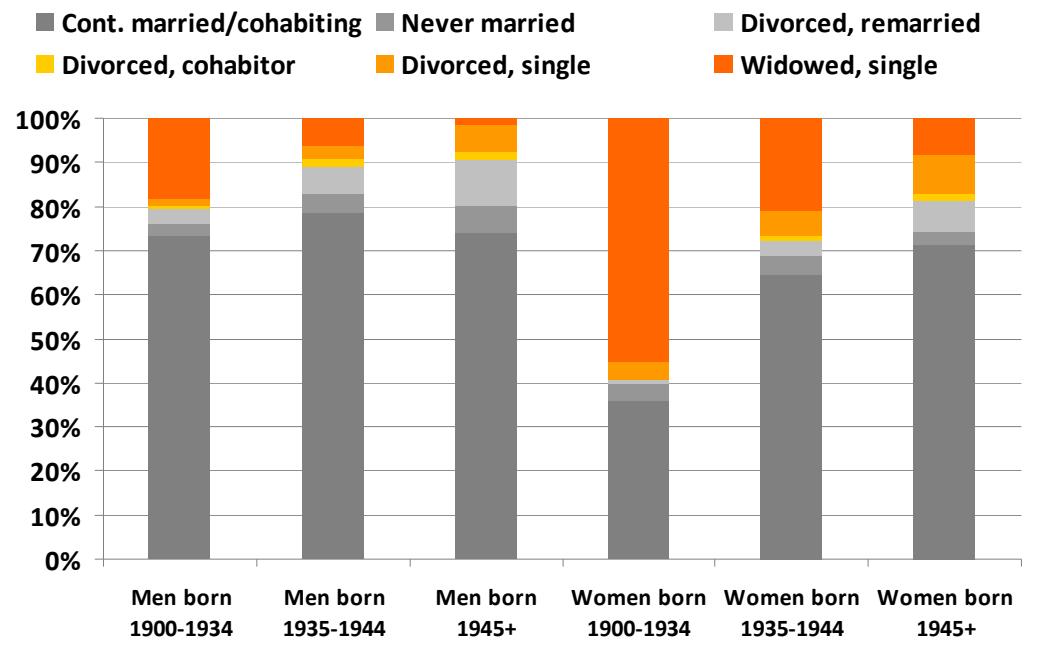

What is the impact of marital history on the rate of home-ownership? Unsurprisingly, Figure 2 shows that continuous marriage or cohabiting is most conducive to ownership; people who never married are less often owner-occupiers. People who experienced a marital dissolution are also less often owner-occupiers. The interesting result is that among those who eventually remarried or entered cohabitation, the rate of ownership is still about 15 percentage points lower, compared to those who never experienced marital dissolution. Those who were owner-occupier but remained single after divorce are less likely to be owner-occupier afterwards. This probably reflects the fact that divorce implies that at least one partner has to move and is thus at risk of exiting home-ownership. In general, there is not much difference between men and women, except for divorcees who are now single, where women appear to fare worse than men.

Figure 9.2: $\quad$ Percentage owner-occupiers, by gender and marital history 


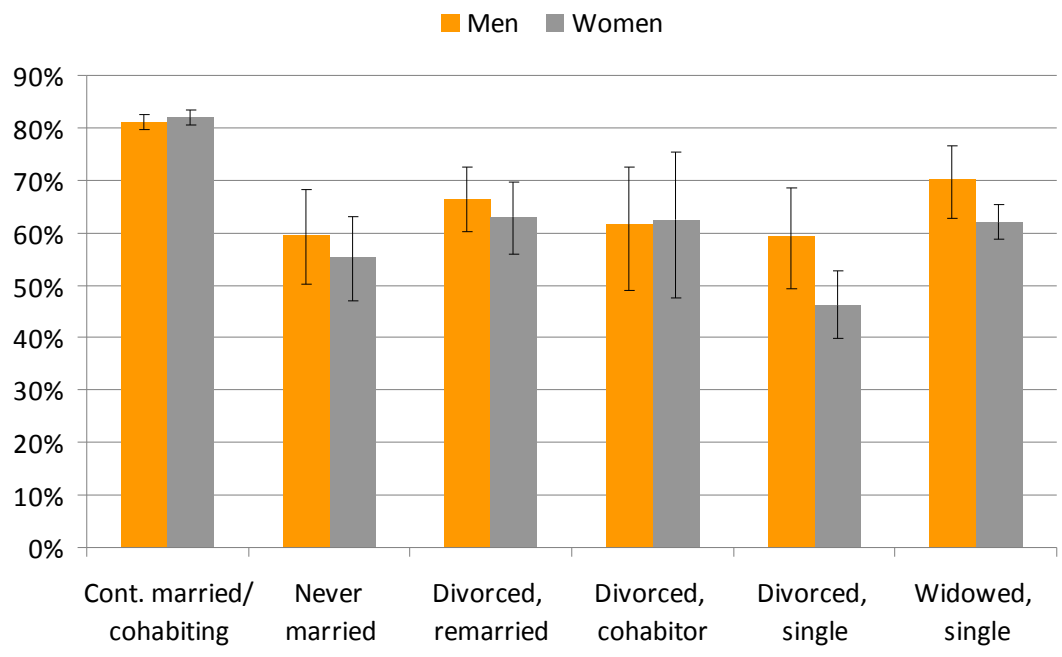

The patterns are a bit less clear when we look at net wealth (Figure 3). Among men and women, individuals who never married enjoy about the same mean level of net wealth as persons who are still in their first marriage. Divorcees who remarried or started cohabiting have a slightly lower mean level of net worth, although the difference is not statistically significant. Individuals who remain single after divorce possess low levels of wealth, and this is clearly true for women. Men who were confronted with the death of the partner and remained single have a higher mean net worth than women in the same situation, and have a higher mean net worth than continuously married individuals. Of course, these results could be due to selection effects, or cohort or country differences, which is why we now turn to the regression results.

Figure 9.3: Mean (geometric) net worth per person in PPP adjusted euro, by gender and marital history 


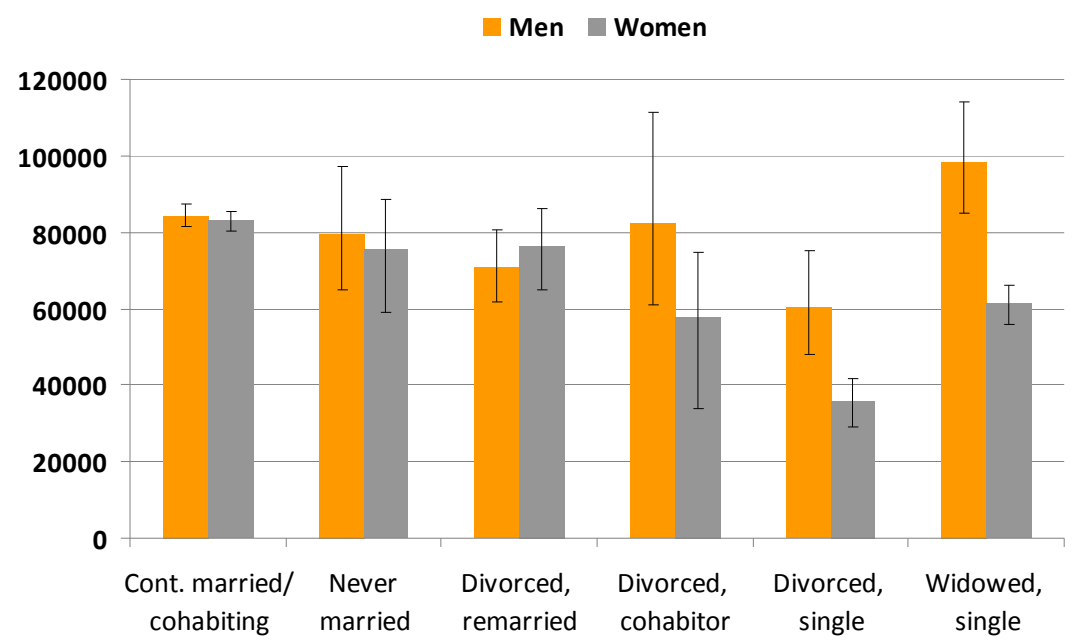

In the regressions we model the natural log of wealth per capita (implying that the regression coefficients can be interpreted as percentage changes), controlling for age, age squared, birth cohort, education, subjective health, number of chronic diseases, number of living children, number of siblings, the degree of urbanisation, and the European region one is living in. Regressions are performed for men and women separately, and by European region. Given the focus of this chapter, we only plot the coefficients for the marital history dummies in Figure 4a en Figure $4 \mathrm{~b}$. The reference category refers to the people who are continuously married. For the models with home-ownership as dependent variable we use logistic regression, but otherwise the model is the same.

Since confidence intervals are large, relative to the estimated coefficients, we must be careful when drawing conclusions. First, in general, marital dissolution has a negative impact (if any) on net wealth and the chance to be a home-owner. Divorcees - both men and women - who remain single, seem to suffer most. The impact is much reduced, and sometimes wholly eliminated, when divorcees remarry. Widowhood seems less disadvantageous than divorce, probably because it does not involve dividing up the assets between partners. In the Northern countries, the impact of marital dissolution is about the same for men and women. This could be due to the higher labour market participation of women in the Scandinavian countries. In the countries of the West (AS, BE, DE, FR), by contrast, divorce and widowhood seem to have a larger impact for women than for men. Coefficient point estimates indicate that these life events seem to have especially negative effects on net wealth for women in the South. For those countries, and also for those of the East, the small number of people in the samples who experienced divorce makes it difficult to identify these effects. 
Figure 9.4a: Impact of marital history categories, relative to those continuously married, on home-ownership, net of control variables, by gender and region (odds-ratios)

Never married Divorced, remarried Divorced, cohabitor Divorced, single $\square$ Widowed, single

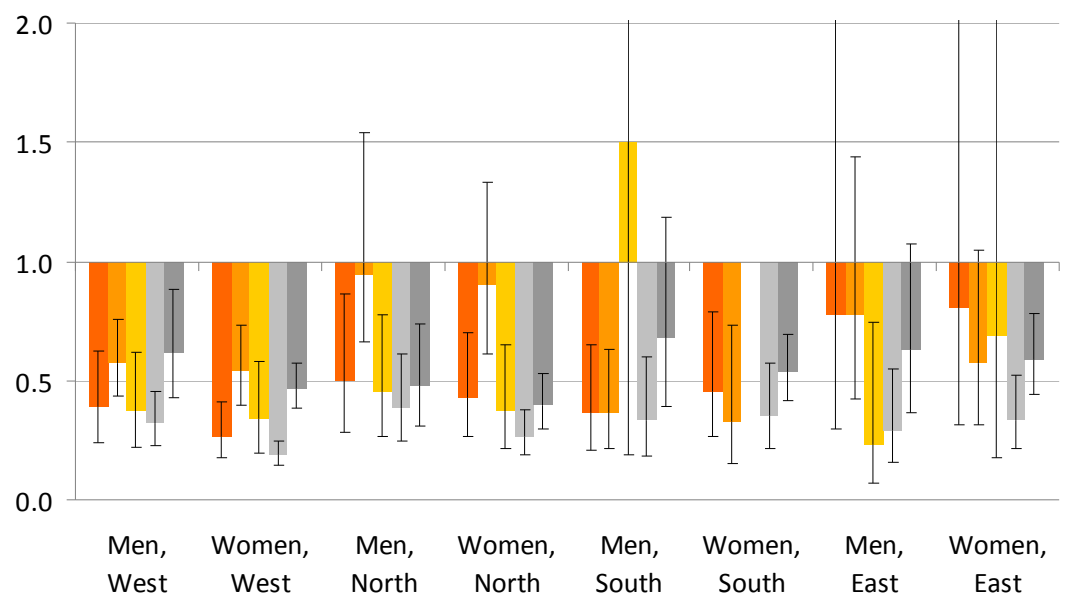

Figure 9.4b: Impact of marital history categories, relative to those continuously married, on net wealth $(\log )$, net of control variables, by gender and region (regression coefficients)

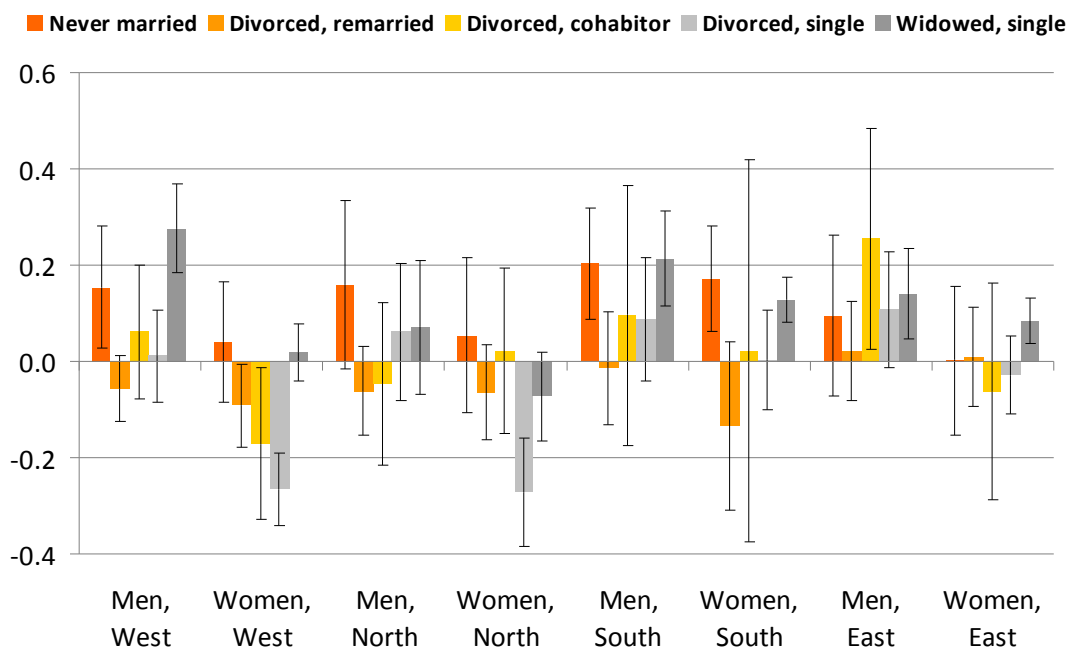

Above, we hypothesised that high female labour market participation would be a variable capturing welfare state influences that may mitigate the impact of marital dissolution for women. In order to test this hypothesis, we estimated separate re- 
gressions for each country (for women only), and plotted the coefficient estimates for the categories 'divorced, single' and 'divorced, remarried' against the female labour market participation rate in 1980. Figure 5 shows the results for net wealth (for home-ownership no relationship emerges in the plots). As regards the coefficient for the category 'divorced, remarried' (5b), we see no pattern. When considering the impact on net wealth of being 'divorced, single' (5a), relative to being continuously married, it seems that in countries where labour market participation is high, e.g. Sweden, this effect is small. When labour market participation is lower, the impact can be much more substantial (e.g. Germany, Italy), but it can also be quite limited (e.g. Spain). The latter may be due to an 'elitist' pattern of divorce, where only women who can afford to do so, having sufficient income of their own, take the step to a marital separation. In any case, the possible impact of this and other context variables needs to be analysed in a more rigorous way.

Figure 9.5a: Impact of divorce on net wealth of being divorced and single, by female labour market participation (country level)

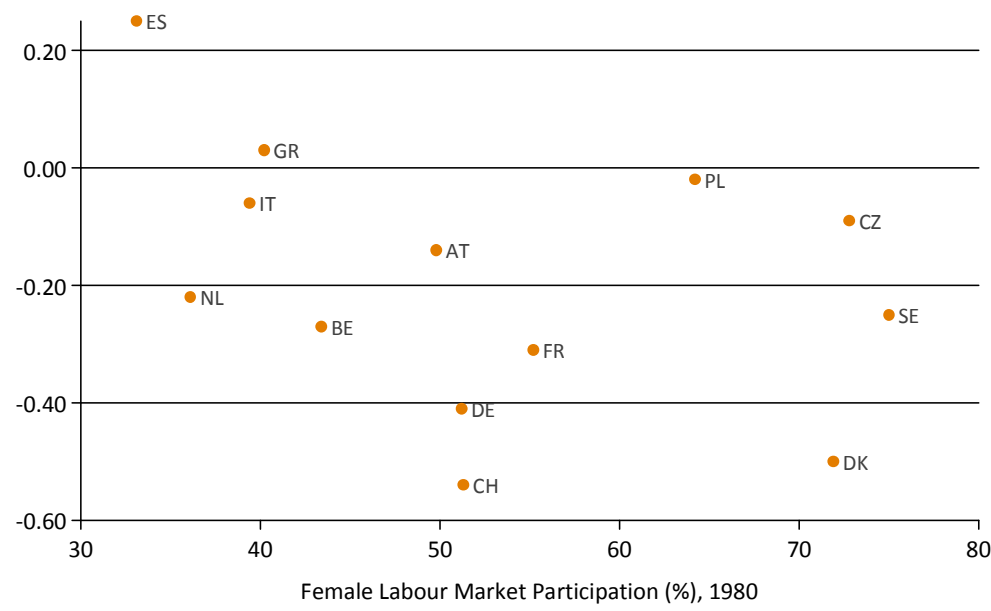

Figure 9.5b: Impact of divorce on net wealth of being divorced and remarried, by female labour market participation (country level) 


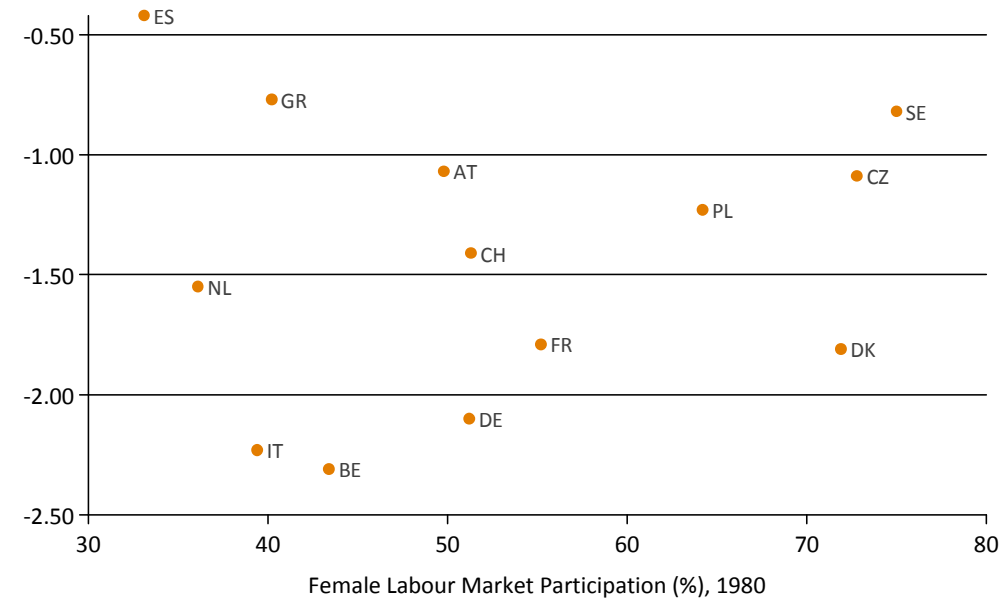

\subsection{Conclusion}

The goal of this study was to examine the impact of marital dissolution at some point during the the life course, particularly divorce, on the wealth of elderly people in Europe. A secondary aim was to assess whether the impact of different marital trajectories would differ across the different welfare state regimes. Our analyses indicate that persons who experienced a divorce have less wealth and lower chances of being home-owners than continuously married persons. Although remarried and cohabiting individuals who have ever experienced a divorce have higher levels of wealth and higher chances of owning the house they are living in, compared to single individuals, we find a lasting effect in old age of marital separation in many countries. This is an interesting result, which could only be obtained by looking at the life histories of individuals. Most research on this topic to date has only considered current marital status, and few studies have looked at the long-term consequences of marital dissolution.

In many countries, but not all, we find larger effects of marital dissolution for women than for men, as expected. We also found mixed support for our hypothesis that there would be large differences between European countries in the impact of marital separation on the wealth of elderly. However, the differences are not easily interpretable in terms of welfare state typologies, or specific welfare state interventions. While the hypothesised mitigating effect of high female labour market participation emerged to some extent from the results, more work is needed to identify such effects with a reasonable degree of certainty. 


\section{References}

Andreß, H.-J., Borgloh, B., Bröckel, M., Giesselmann, M. and Hummelsheim, D. 2006 'The Economic Consequences of Partnership Dissolution. A Comparative Analysis of Panel Studies from Belgium, Germany, Great Britain, Italy and Sweden'. European Sociological Review, Vol. 22(5), pp. 533-560.

Dewilde, C. 2008 'Divorce and the Housing Movements of Owner-Occupiers: A European Comparison'. Housing Studies, Vol. 23(6), pp. 809-832.

- 2009 'Divorce and Housing: A European Comparison of the Housing Consequences of Divorce for Men and Women', in H.-J. Andreß and D. Hummelsheim (eds) When Marriage Ends. Economic and Social Consequences of Partnership Dissolution, Cheltenham: Edward Elgar.

Dewilde, C. and Uunk, W. 2008 'Remarriage as a Way to Overcome the Financial Consequences of Divorce. A Test of the Economic Need-Hypothesis for European Women'. European Sociological Review: pp. 393-407.

Halvorst, R. and Palmquist, R. 1980 'The Interpretation of Dummy Variables in Semilogarithmic Equations'. American Economic Review, Vol. 70(3), pp. 474-475.

International Labour Organization (ILO). 2010 'Key Indicators of the Labour Market Programme', Date retrieved June 5th, 2010, from http://kilm.ilo.org/KILMnetBeta/default2.asp

Uunk, W. 2004 'The Economic Consequences of Divorce for Women in the European Union: The Impact of Welfare State Arrangements'. European Journal of Population, Vol. 20, pp. 251-285.

Winkler, A. 1997 'Economic Decision-Making by Cohabitors: Findings Regarding Income Pooling'. Applied Economics, Vol. 29(8), pp. 1079-1090.

Wilmoth, J. and Koso, G. 2002 'Does Marital History Matter? Marital Status and Wealth Outcomes among Preretirement Adults'. Journal of Marriage and Family, Vol. 64(1), pp. 254268 . 